\title{
An observational study of post cardiac arrest management at a uk tertiary intensive care unit between 2010 and 2012
}

\author{
A Mahal ${ }^{1 *}$, A Curtis $^{2}$, R Gray ${ }^{2}$ \\ From ESICM LIVES 2015 \\ Berlin, Germany. 3-7 October 2015
}

\begin{abstract}
Introduction
Patients surviving cardiac arrest account for $5.8 \%$ of all UK ICU admissions ${ }^{1}$. Analysis of the Intensive Care National Audit and Research Centre Case Mix Programme Database (ICNARC CMPD) found that $42.9 \%$ of patients admitted after cardiac arrest survived to ICU discharge, and $28.6 \%$ survived to hospital discharge. Of these $79.9 \%$ returned directly home ${ }^{1}$.
\end{abstract}

\section{Objectives}

To see if our outcomes were comparable to published data and to audit care against the UK Intensive Care Society (ICS) guidelines ${ }^{2}$.

\section{Methods}

Data was collected from our ICU electronic information system, including cardiac arrest in or out of hospital (IHCA/OHCA) and initial cardiac rhythm, either Ventricular Fibrillation/Tachycardia (VF/VT) or Asystole/ Pulseless Electrical Activity (PEA). We recorded implementation of the ICS Post Cardiac Arrest Care Bundle, comprising; coronary reperfusion, haemodynamic optimisation, control of ventilation, blood glucose, temperature and seizures. Hospital survival and discharge data were collected from the electronic hospital discharge database.

\section{Results}

161 patients were admitted post cardiac arrest between January 2010 and December 2012. 6 patients were excluded due to incomplete data. There were $60 \mathrm{IHCA}$, $65 \%$ male (mean age, 68 years) and 35\% female (mean age, 61 years) and 95 OHCA, 69\% male (mean age, 66 years)

${ }^{1}$ Brighton and Sussex Medical School, Brighton, United Kingdom

Full list of author information is available at the end of the article and $31 \%$ female (mean age, 70 years). Comorbidities included cardiovascular (36\%), gastrointestinal (20\%) and drug/alcohol abuse (17\%).

The predominant rhythm was VF/VT (56\%) in OHCA and Asystole/PEA (65\%) in IHCA. 98\% of patients were mechanically ventilated and $79 \%$ required haemodynamic optimisation with inotropic agents. Adequate blood glucose control was achieved in $72 \%$ of patients. Primary PCI was performed in 20\% VF/VT OHCA. Cooling was achieved in $78 \%$ of VF/VT OHCA compared to $24 \%$ of VF/VT IHCA.

$58 \%$ of the cohort died during hospital admission, $86 \%$ during their ICU stay. However $42 \%$ went on to survive to hospital discharge, $78 \%$ of whom were discharged home (33\% of all patients admitted). The best outcome was seen in VF/VT IHCA and VF/VT OHCA; $62 \%$ and $50 \%$ respectively survived to hospital discharge. In VF/VT IHCA 77\% of hospital survivors were discharged home compared to $81 \%$ in VF/VT OHCA. Poorest outcome was observed in PEA/Asystole OHCA where 27\% survived to hospital discharge.

\section{Conclusions}

Comparing our population to the ICNARC CMPD data, survival to hospital discharge (33\% vs. $28.6 \%)$ and subsequent discharge home ( $78 \%$ vs. $79.9 \%)$ were comparable. Adherence to the ICS bundle of care was well achieved overall. The poorest component of the bundle was provision of primary PCI for OHCA VF/VT.

\section{Authors' details}

'Brighton and Sussex Medical School, Brighton, United Kingdom. ${ }^{2}$ Brighton and Sussex University Hospitals Trust, Intensive Care Unit, Brighton, United Kingdom.

\section{SpringerOpen ${ }^{\circ}$}

( 2015 Mahal et al.; This is an Open Access article distributed under the terms of the Creative Commons Attribution License (http:// creativecommons.org/licenses/by/4.0), which permits unrestricted use, distribution, and reproduction in any medium, provided the original work is properly cited. 


\section{References}

1. Nolan JP, et al: Outcome following admission to UK intensive care units after cardiac arrest: a secondary analysis of the ICNARC Case Mix Programme Database. Anaesthesia 2007, 62:1207-16.

2. Standards for the management of patients after cardiac arrest. Intensive Care Society 2008.

doi:10.1186/2197-425X-3-S1-A199

Cite this article as: Mahal et al:: An observational study of post cardiac arrest management at a uk tertiary intensive care unit between 2010 and 2012. Intensive Care Medicine Experimental 2015 3(Suppl 1):A199.

\section{Submit your manuscript to a SpringerOpen ${ }^{\mathcal{O}}$ journal and benefit from:}

- Convenient online submission

- Rigorous peer review

- Immediate publication on acceptance

- Open access: articles freely available online

- High visibility within the field

- Retaining the copyright to your article

Submit your next manuscript at $\gg$ springeropen.com 